\title{
Short communication: Genetic variation of riboflavin content in bovine milk
}

\author{
Nina A. Poulsen, ${ }^{* 1}$ Iga Rybicka, $†$ Lotte B. Larsen, ${ }^{*}$ Albert J. Buitenhuis, $\ddagger$ and Mette K. Larsen* \\ *Department of Food Science, Aarhus University, DK-8830 Tjele, Denmark \\ †Department of Technology and Instrumental Analysis, Poznan University of Economics, Poznan 61-875, Poland \\ ¥Center for Quantitative Genetics and Genomics, Department of Molecular Biology and Genetics, Aarhus University, DK-8830 Tjele, Denmark
}

\begin{abstract}
Riboflavin (vitamin $\mathrm{B}_{2}$ ) is an essential water-soluble vitamin; elderly people and adolescents in particular can have poor riboflavin status. In Western diets, milk and dairy products are primary sources of riboflavin, but little is known about the natural variation within and among bovine breeds, and how genetic and environmental factors can affect the riboflavin content in milk. As a part of the Danish-Swedish Milk Genomics Initiative, the aim of the study was to quantify milk riboflavin content using reverse-phase HPLC in 2 major Danish dairy breeds. The results showed substantial interbreed differences in milk riboflavin content. Milk from Danish Jersey cows contained significantly higher levels of riboflavin $(1.93 \mathrm{mg} / \mathrm{L}$ of milk) than milk from Danish Holstein cows (1.40 mg/L of milk). Furthermore, genetic analyses revealed high heritabilities in both breeds (0.52 for Danish Holstein and 0.31 for Danish Jersey). A genomic association study found 35 significant single nucleotide polymorphisms (false discovery rate $<0.10)$ to be associated with riboflavin content in milk in Jersey cows (all on BTA14 and BTA17), and 511 significant single nucleotide polymorphisms in Holstein cows spread over 25 different autosomes with BTA13 and BTA14 having the most promising quantitative trait loci. The best candidate gene found within the identified quantitative trait loci was SLC52A3, a riboflavin transporter gene, which was among the significant markers on BTA13 in Holstein cows.
\end{abstract}

Key words: genomic heritability, quantitative trait loci, vitamin $\mathrm{B}_{2}$

\section{Short Communication}

Milk, as an important source of nutrients, is recommended as part of an everyday, balanced diet. Milk contains saturated and unsaturated fatty acids, proteins, carbohydrates, minerals, and vitamins, which in their

Received September 8, 2014.

Accepted January 28, 2015.

${ }^{1}$ Corresponding author: Nina.Poulsen@agrsci.dk natural or hydrolyzed form potentially promote positive health effects. Consumption of milk and dairy products can thereby exert protective effects on human health (Haug et al., 2007; Givens, 2010). Undoubtedly bovine milk is one of the best sources for several vitamins and minerals in human nutrition, including riboflavin (vitamin $\mathrm{B}_{2}$ ) and cobalamin (vitamin $\mathrm{B}_{12}$; Rooke et al., 2010). Riboflavin belongs to the essential water-soluble vitamins in milk, and according to Haug et al. (2007), the content in bovine milk is around $1.83 \mathrm{mg} / \mathrm{L}$. Riboflavin is important due to its key role in numerous metabolic pathways and redox reactions through the biologically active coenzymes, flavin adenine dinucleotide, and flavin mononucleotide (Powers, 2003). For elderly people and adolescents in particular, low intake of riboflavin-containing foods can result in riboflavin deficiencies, and in Western diets milk and dairy products account for $51 \%$ of the intake in preschool children (Powers, 2003).

Despite the acknowledged value of milk and dairy products as riboflavin sources (Sunaric et al., 2012), very few studies have documented the drivers for riboflavin variation in milk within and across bovine breeds. The primary origin of riboflavin and other B vitamins is biosynthesis in the rumen (Schwab et al., 2006), and documented effects of feed and breed (Shingfield et al., 2005; Poulsen et al., 2015) are related to the rumen environment and the microbial processes responsible for the riboflavin synthesis or transport and secretion of riboflavin into milk.

The aim of this study was to determine the content of riboflavin in milk from Danish Holstein (DH) and Danish Jersey (DJ) cows and to explore to what extent this variation can be explained by genotype. Furthermore, the aim was to identify QTL for milk riboflavin content using the BovineHD BeadChip. To our knowledge, this is the first study to screen riboflavin variation in milk from a large number of animals and to provide heritability estimation and QTL identification for milk riboflavin content.

This study was conducted as part of the DanishSwedish Milk Genomics Initiative. Ear tissue and morning milk samples were collected from $456 \mathrm{DH}$ (20 dairy herds, October-December 2009) and 436 DJ (22 dairy 
herds, February-April 2010) as described by Poulsen et al. (2012). Parity and days in milk at sampling were registered for all cows. Milk yield at morning milking was recorded, and representative milk samples of at least $0.5 \mathrm{~L}$ were placed on ice and transported to the laboratory. Immediately after arrival to the laboratory, milk samples were skimmed (centrifuged for $30 \mathrm{~min}$, $2,643 \times g$ at $4^{\circ} \mathrm{C}$ ), aliquoted, and stored at $-20^{\circ} \mathrm{C}$ until analysis of riboflavin.

The day before analysis, samples were moved to $4^{\circ} \mathrm{C}$ and riboflavin content in skim milk samples was determined by reverse-phase HPLC essentially as described in Poulsen et al. (2015). The HPLC system consisted of a Zorbax SB-C8 column $(4.6 \times 150 \mathrm{~nm}, 5 \mu \mathrm{m})$ equipped with a fluorescence detector (Agilent FLD 1200, Agilent Technologies, Waldbronn, Germany). All analytical procedures were conducted under subdued lighting conditions using glassware wrapped in aluminum foil. In total, riboflavin content was determined in milk from 395 DJ and $428 \mathrm{DH}$ cows.

Genomic DNA was extracted from ear tissue, which was used for genotyping $347 \mathrm{DH}$ and 290 DJ cows with the bovine HD beadchip (Van Tassell et al., 2008). These cows were daughters of $200 \mathrm{DH}$ and 133 DJ sires. The genotyping was performed with the Illumina Infinium II Multisample assay device (Illumina Inc., San Diego, CA). The SNP chips were scanned using iScan and analyzed by Beadstudio, version 3.1 (Illumina Inc.). The quality parameters, used for the selection of SNP in the genome-wide association studies, were minimum call rates of $80 \%$ for individuals and $95 \%$ for loci. Marker loci with minor allele frequencies below $1 \%$ were excluded. The quality of the markers was assessed using the GenCall data analysis software of Illumina. Individuals with average GenCall scores below 0.65 were excluded (Teo et al., 2007). The Bos taurus genome assembly (Btau_4.0; Liu et al., 2009) was used to base the physical positions of the markers.

Breed difference in milk riboflavin content was estimated by one-way ANOVA:

$$
\mathrm{Y}_{\mathrm{ik}}=\mu+\text { breed }_{\mathrm{i}}+\mathrm{e}_{\mathrm{ik}},
$$

where $Y_{i k}$ is the phenotype of individual $k$ in breed $i$, $\mu$ is the overall mean of the trait, and breed is a fixed effect $(\mathrm{i}=\mathrm{DJ}, \mathrm{DH})$.

Variance components were estimated within breed following a linear model:

$\mathrm{Y}_{\mathrm{ijk}}=\mu+$ parity $_{\mathrm{i}}+\mathrm{DIM}+\operatorname{herd}_{\mathrm{j}}+\operatorname{animal}_{\mathrm{k}}+\mathrm{e}_{\mathrm{ijk}},[2]$

where $Y_{i j k}$ is the phenotype of individual $k$ in parity $\mathrm{i}$ and herd $\mathrm{j}, \mu$ is the fixed mean effect, parity is a fixed effect ( $\mathrm{i}=1,2,3 \mathrm{DH}, \mathrm{i}=1,2,3 \mathrm{DJ}$ ), DIM is a covariate of days in milk (d 129 to 229 in DH, d 130 to 252 in DJ), herd is a random effect, and animal is the random additive genetic effect based on $\mathbf{G}$ of animal $\mathrm{k}$ (Yang et al., 2010).Univariate analyses were performed to estimate the heritability, which was defined as

$$
\mathrm{h}^{2}=\sigma_{\mathrm{a}}^{2} /\left(\sigma_{\mathrm{a}}^{2}+\sigma_{\text {herd }}^{2}+\sigma_{\mathrm{e}}^{2}\right),
$$

where $\sigma_{a}^{2}$ was the genetic variation, $\sigma_{\text {herd }}^{2}$ was the herd variation, and $\sigma_{e}^{2}$ was the residual variation obtained from model 2.The proportion of the total variance caused by the herd was calculated as

$$
\mathrm{h}_{\text {herd }}=\sigma_{\text {herd }}^{2} /\left(\sigma_{a}^{2}+\sigma_{\text {herd }}^{2}+\sigma_{\mathrm{e}}^{2}\right) .
$$

A genomic relationship matrix was calculated for each breed separately as described by the first method presented in VanRaden (2008). A genomic relationship matrix was calculated as follows: Let $\mathbf{M}$ be a matrix with dimensions of the number of individuals $(n)$ by the number of loci $(m)$ that specifies which marker alleles each individual inherited. The elements of $\mathbf{M}$ were set to $-1,0,1$ for the homozygote, heterozygote, and the other homozygote, respectively. The diagonals of $\mathbf{M}^{\prime} \mathbf{M}$ show the number of homozygous loci for each individual, and off diagonals measure the number of alleles shared by relatives. Let the frequency of the second allele at locus $i$ be $p_{i}$, and let $\mathbf{P}$ contain the allele frequencies, such that column $i$ of $\mathbf{P}$ equals $2\left(p_{i}-0.5\right)$. Subtraction of $\mathbf{P}$ from $\mathbf{M}$ gives $\mathbf{Z}$, which is needed to set the expected mean value to 0 . The genomic relationship matrix $\mathbf{G}$ was then calculated as $\mathbf{Z Z} \mathbf{Z}^{\prime} /\left[2 \Sigma p_{i}(1\right.$ - $p_{i}$ )] (VanRaden, 2008).

Association Mapping. The analysis was performed using the following linear model for each breed separately:

$$
\begin{gathered}
\mathrm{Y}_{\mathrm{ijk}}=\mu+\operatorname{herd}_{\mathrm{i}}+\operatorname{parity}_{\mathrm{j}}+\mathrm{DIM}+\mathrm{b} \times \mathrm{SNP} \\
+\operatorname{animal}_{\mathrm{k}}+\mathrm{e}_{\mathrm{ijk}},
\end{gathered}
$$

where $Y_{i j k}$ is the phenotype of individual $k$ in herd $i$ and parity $\mathrm{j}, \mu$ is the fixed mean effect, herd is a fixed effect ( $\mathrm{i}=1,2, \ldots, 20 \mathrm{DH} ; \mathrm{i}=1,2, \ldots, 21 \mathrm{DJ})$, parity is a fixed effect $(\mathrm{j}=1,2,3 \mathrm{DH}, \mathrm{j}=1,2,3 \mathrm{DJ})$, DIM is a covariate of days in milk (d 129 to 229 in DH, d 130 to 252 in DJ), b is the allele substitution effect, which is a count in individual $\mathrm{k}$ of one of the 2 alleles (with arbitrary labeling), and animal is the random additive genetic effect based on $\mathbf{G}$ of animal k (Yang et al., 2010). A Wald test with a null hypothesis of $\mathrm{H}_{0}$ : $\mathrm{b}=$ 


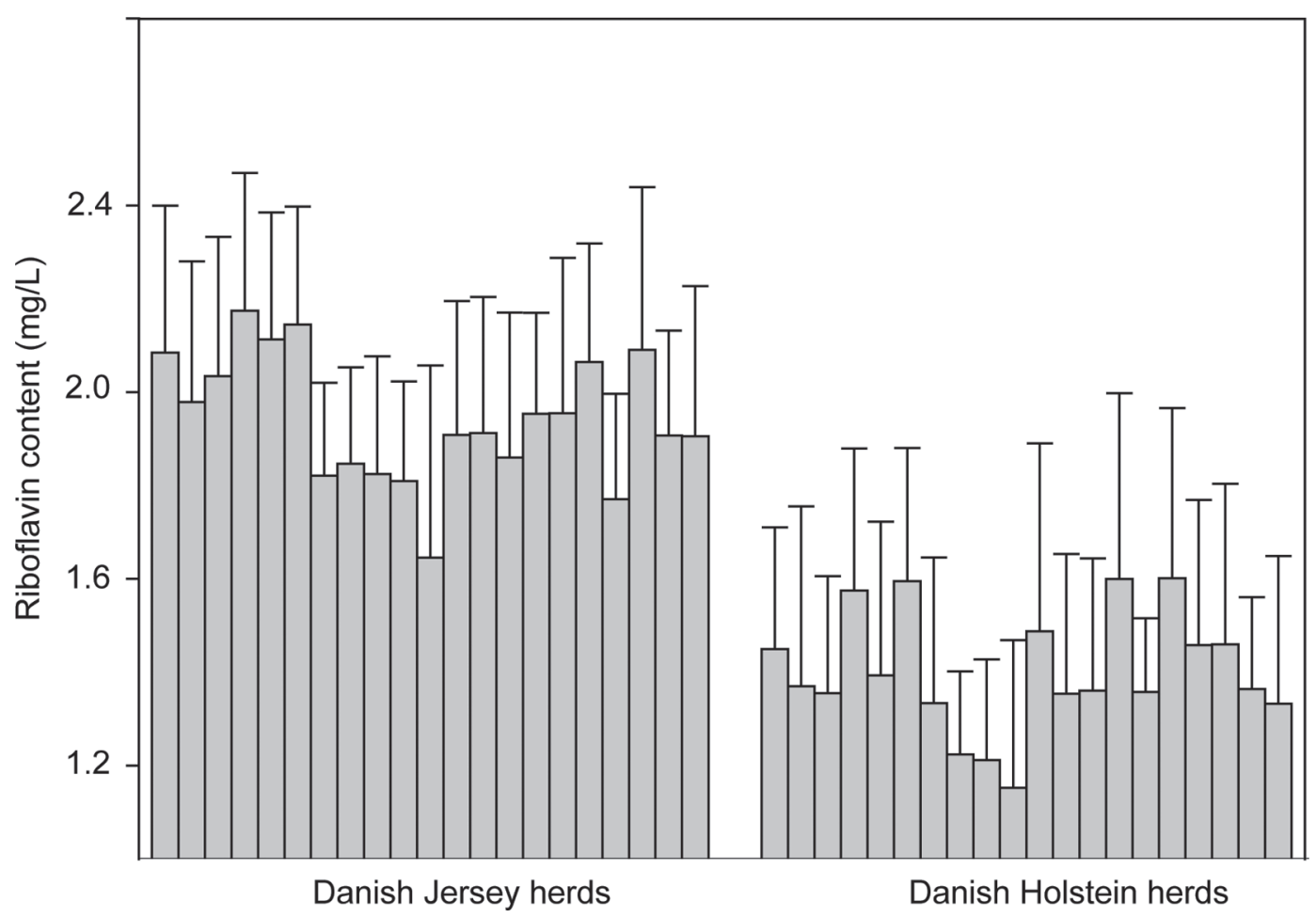

Figure 1. Mean $( \pm \mathrm{SD})$ riboflavin content $(\mathrm{mg} / \mathrm{L})$ from Danish Jersey $(\mathrm{n}=21)$ and Danish Holstein $(\mathrm{n}=20)$ herds.

0 was used to test the effect of the SNP. The analyses were performed using REML in the R interface of DMU (Madsen and Jensen, 2007; available at http://dmu. agrsci.dk). Significance thresholds were determined using a false discovery rate correction using the $\mathrm{R}$ package "qvalue" version 1.34.0. A false discovery rate of $P$ $<0.10$ was considered significant.

The results showed substantial interbreed difference in milk riboflavin content (Figure 1) with DJ cows having significantly $(P<0.001)$ higher levels $(1.93 \mathrm{mg} / \mathrm{L}$ of milk, CV 16\%) compared with DH cows $(1.40 \mathrm{mg} / \mathrm{L}$ of milk, CV 23\%). In DJ cows, the riboflavin content varied from 1.02 to $2.84 \mathrm{mg} / \mathrm{L}$ of milk and in $\mathrm{DH}$ cows from 0.73 to $2.83 \mathrm{mg} / \mathrm{L}$ of milk. These concentrations are within the range reported in the literature (Lindmark-Mansson et al., 2003; Haug et al., 2007), and the difference between breeds is similar to that previously reported (Hand and Sharp, 1939; Theophilus and Stamberg, 1945). The higher milk riboflavin content in DJ milk compared with DH milk is largely due to milk from DJ cows being more concentrated than milk from DH cows, as also reflected in lower yield and higher protein and fat contents (Poulsen et al., 2012). To examine the relationship to yield further, we estimated genetic correlations between riboflavin content and milk yield; however, due to high standard errors these results were not reported.
In both breeds, neither parity nor DIM affected milk riboflavin content. Theophilus and Stamberg (1945) found that milk from individual cows remained rather constant on a daily basis regardless of varying milk yield. During lactation, an inverse relation between milk yield and riboflavin content has been found, with increasing riboflavin content in late lactation, when milk yield is lowered (Theophilus and Stamberg, 1945). Here, only cows in mid lactation were sampled, and an effect of DIM was therefore not observed. Furthermore, low variation was observed in the riboflavin content among herds (Figure 1), and the herd variance explained only about $10 \%$ of the total variance in $\mathrm{DH}$ and DJ (Table 1).

The genetic variance explained a substantial amount of the variation, and estimated heritabilities were high $\left(\right.$ Holstein $\mathrm{h}^{2}=0.52$ and Jersey $\mathrm{h}^{2}=0.31$; Table 1 ). The low herd variances and high heritabilities for both breeds suggest that the riboflavin content in milk is under significant genetic influence and could be changed through selective breeding. Here, herd variance was modeled as a random effect, which inflated the total phenotypic variance compared with other studies where herd variance was included as a fixed effect. Excluding herd variance from the heritability estimation increase the estimates slightly to 0.58 for $\mathrm{DH}$ and 0.36 for DJ. The heritability estimate in DH is higher than those 
Table 1. Variance components, heritability ${ }^{1}\left(h^{2}\right)$, and part of phenotypic variance for milk riboflavin content explained by herd ${ }^{2}\left(h_{\text {herd }}\right)$ for Danish Holstein and Danish Jersey cows

\begin{tabular}{lcccccc}
\hline Breed & $\begin{array}{c}\text { Riboflavin mean, } \\
\mathrm{mg} / \mathrm{L}(\mathrm{SE})\end{array}$ & $\sigma_{\text {animal }}^{2}$ & $\sigma_{\text {herd }}^{2}$ & $\sigma_{\text {residual }}^{2}$ & $\mathrm{~h}^{2}(\mathrm{SE})$ & $\mathrm{h}_{\text {herd }}(\mathrm{SE})$ \\
\hline Danish Holstein & $1.40(0.32)$ & 0.051 & 0.010 & 0.036 & $0.52(0.17)$ & $0.10(0.05)$ \\
Danish Jersey & $1.93(0.30)$ & 0.026 & 0.011 & 0.048 & $0.31(0.16)$ & $0.13(0.07)$ \\
\hline${ }^{1} \mathrm{~h}^{2}=\sigma_{\text {animal }}^{2} / \sigma_{\text {phenotypic }}^{2}, \sigma_{\text {phenotypic }}^{2}=\sigma_{\text {animal }}^{2}+\sigma_{\text {herd }}^{2}+\sigma_{\text {residual }}^{2} \cdot$ & & & \\
${ }^{2} \mathrm{~h}_{\text {herd }}=\sigma_{\text {herd }}^{2} / \sigma_{\text {phenotypic }}^{2}$
\end{tabular}

estimated for milk production traits and individual fatty acids using the same DH data (Buitenhuis et al., 2013; Krag et al., 2013), and similar to that estimated for some milk metabolites (Buitenhuis et al., 2013). Like riboflavin, vitamin $\mathrm{B}_{12}$ is of microbial origin, and in Dutch Holstein Friesian cows vitamin $\mathrm{B}_{12}$ had an estimated heritability of 0.37 , which also suggests that vitamin $\mathrm{B}_{12}$ content in milk can be changed through genetic selection (Rutten et al., 2013).

The results of the genome-wide association studies are presented in Supplemental Table S1 (http://dx.doi. org/10.3168/jds.2014-8829) for DH and Supplemental Table S2 (http://dx.doi.org/10.3168/jds.2014-8829) for DJ including the allele-substitution effect and location. Thirty-five significant SNP $\left[-\log _{10}(P\right.$-value $\left.)>3\right]$ were found to be associated with riboflavin in DJ and 511 significant SNP in DH. In DJ, significant SNP associations were detected on BTA14, BTA16, and BTA17, and some could be assigned to known genes (DGAT1, HEATR7A, PYCRL, BAI1, TSNARE1, FAM135B, $H M C N 1$, and TMEM132D). For DH 170, significant SNP could be assigned to 64 genes, and within these 55 SNP were assigned to 19 genes on BTA14. The SNP, ARS-BFGL-NGS-24603 with the highest $-\log _{10}(P$ value) for $\mathrm{DH}$, was located on BTA13 and assigned to $S L C 52 A 3$, which is a riboflavin transporter gene (Figure 2 , explaining $2 \%$ of the total variation. In addition, several of the SNP on BTA14 had very high $-\log _{10}(P$-value) including those assigned to ARHGAP39, CYHR1, CPSF1, DGAT1, SMPD5, and GRINA. Five significant SNP were overlapping between DH and DJ, and all of these were located on BTA14. Four SNP were assigned to known genes; DGAT1 (ARS-BFGL-NGS-4939), PYCRL (BOVINEHD1400000331), and BAI1 (BOVINEHD1400000487 and BOVINEHD1400000489), whereas BOVINEHD1400000485 could not be assigned to any gene.

To our knowledge, this is the first GWA study for milk riboflavin content. All common significant SNP were located on BTA14. The BTA14, and especially DGAT1, has been intensively studied, and the chromosomal region around DGAT1 is shown to affect several milk composition traits both related to economically important traits, milk metabolites and milk fatty acid composition (Schennink et al., 2009; Stoop et al., 2009; Buitenhuis et al., 2013; Melzer et al., 2013). The DGAT1 codes for an enzyme responsible for the esterification of fatty acyl-CoA in the synthesis of triglycerides (Grisart et al., 2002), and explains a major part of the variation in the fatty acid composition (Schennink et al., 2007, 2009; Stoop et al., 2009), but also show a strong effect on milk yield (Schennink et al., 2007). Here, one of the common significant SNP was also found to be associated with DGAT1. This suggests a broader influence of this gene and the regions in close proximity to the gene on milk production and composition.

The major candidate gene found in this study was SLC52A3, which is one of the riboflavin transporter genes identified in mammals (Yonezawa and Inui, 2013). A homolog to the riboflavin transporter genes has been shown to transport and catalyze uptake of riboflavin in Saccharomyces cerevisiae (Reihl and Stolz, 2005), but also human and rat riboflavin plasma transporter genes have been identified and functionally characterized (Yonezawa et al., 2008; Yamamoto et al., 2009). The SLC52A3 explained $2 \%$ of the variation in milk riboflavin content in milk, and could be a good candidate gene responsible for the genetic regulation of riboflavin content in Holstein milk. The strong QTL in a riboflavin transporter gene suggests that the genetic control of riboflavin content is mainly related to plasma transport rather than to factors related to microbial metabolism in the rumen.

The high heritabilities and strong genetic influence were reflected in low herd variances suggesting that management only plays a minor role in riboflavin content in milk. Selection of animals included in the study could have affected the result because the selection has been done to maximize genetic distance among animals and minimize environmental variation, and the variation in feed components is low and similar among Jersey and Holstein herds (Poulsen et al., 2012).

From the present results, we conclude that variation in riboflavin content in milk is mainly related to genetic factors, and $S L C 52 A 3$, which is a riboflavin transporter gene, is thought to play a major role in milk riboflavin regulation. However, the underlying mechanism still needs to be explored through more directed studies. 


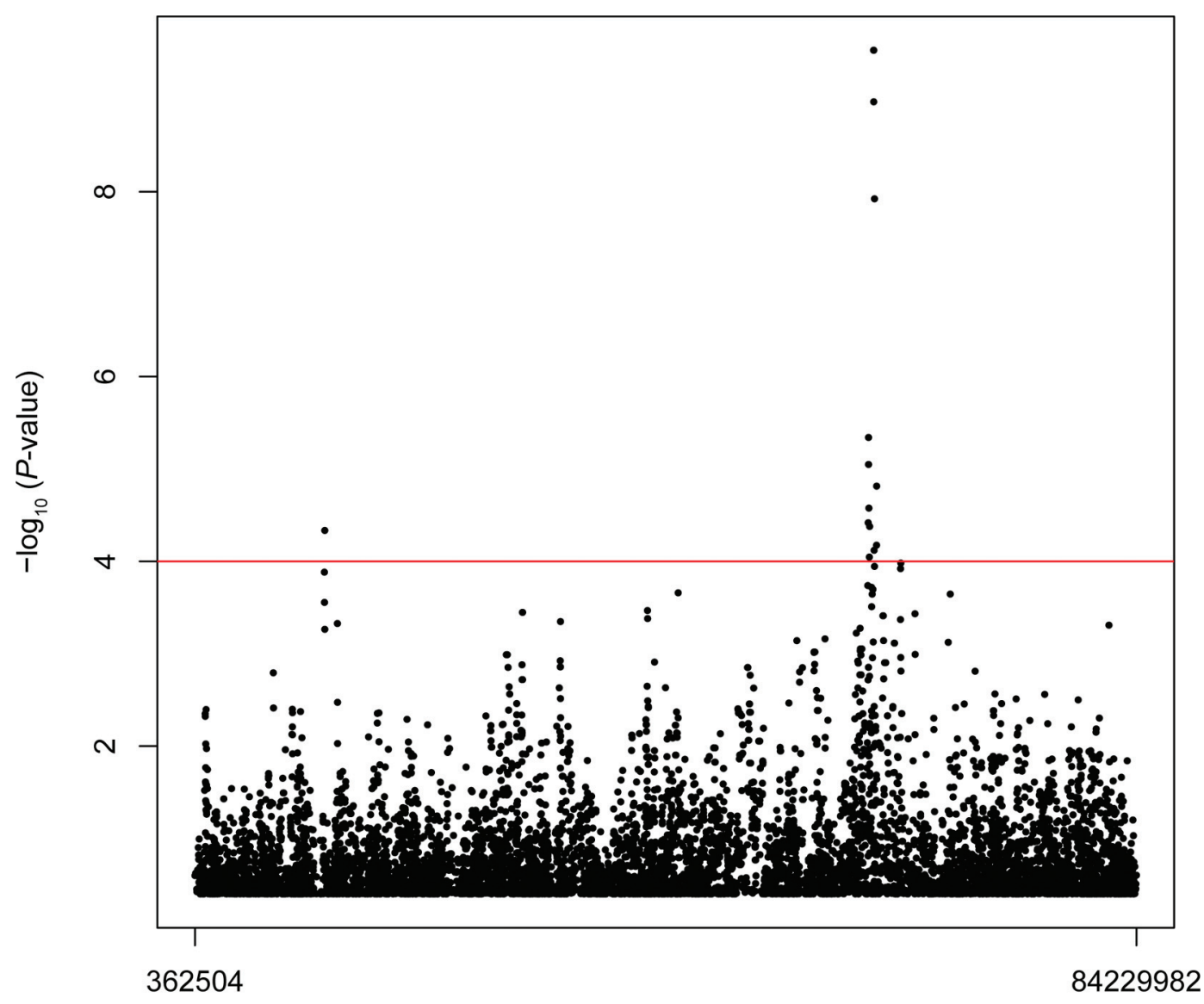

Chromosome (bp)

Figure 2. Plot of the QTL detected on BTA13 for riboflavin in Danish Holstein cattle. The x-axis represents the chromosome length in base pairs. The y-axis represents the $-\log _{10}(P$-value $)$. Each dot represents a SNP marker ordered based on the location on the chromosome. The horizontal (red) line represents the false discovery rate $<0.10$ significance level. Color version available online.

\section{ACKNOWLEDGMENTS}

This work was supported by grants from Arla Foods (Viby J, Denmark), the Danish Cattle Federation (Aarhus, Denmark), the Danish Strategic Research Council (Copenhagen K, Denmark), Aarhus University (Aarhus, Denmark), and the Milk Levy Fund (Aarhus N, Denmark) through the "Milk Genomics" and "Phenotypic and genetic markers for specific milk quality parameters" projects. The sampling and analysis team at the Danish-Swedish Milk Genomics Initiative is gratefully acknowledged for excellent technical assistance.

\section{REFERENCES}

Buitenhuis, A. J., U. K. Sundekilde, N. A. Poulsen, H. C. Bertram, L. B. Larsen, and P. Sørensen. 2013. Estimation of genetic parameters and detection of quantitative trait loci for metabolites in Danish Holstein milk. J. Dairy Sci. 96:3285-3295.

Givens, D. I. 2010. Milk and meat in our diet: Good or bad for health? Animal 4:1941-1952.
Grisart, B., W. Coppieters, F. R. Farnir, L. Karim, C. Ford, P. Berzi, N. Cambisano, M. Mni, S. Reid, P. Simon, R. Spelman, M. Georges, and R. Snell. 2002. Positional candidate cloning of a QTL in dairy cattle: Identification of a missense mutation in the bovine $D G A T 1$ gene with major effect on milk yield and composition. Genome Res. 12:222-231.

Hand, D. B., and P. F. Sharp. 1939. The riboflavin content of cow's milk. J. Dairy Sci. 22:779-783.

Haug, A., A. Høstmark, and O. Harstad. 2007. Bovine milk in human nutrition-A review. Lipids Health Dis. 6:25.

Krag, K., N. A. Poulsen, M. K. Larsen, L. B. Larsen, L. L. Janss, and A. J. Buitenhuis. 2013. Genetic parameters for milk fatty acids in Danish Holstein cattle based on SNP markers using a Bayesian approach. BMC Genet. 14:79.

Lindmark-Mansson, H., R. Fonden, and H. E. Pettersson. 2003. Composition of Swedish dairy milk. Int. Dairy J. 13:409-425.

Liu, Y., X. Qin, X. Z. Song, H. Jiang, Y. Shen, K. J. Durbin, S. Lien, M. P. Kent, M. Sodeland, Y. Ren, L. Zhang, E. Sodergren, P. Havlak, K. C. Worley, G. M. Weinstock, and R. A. Gibbs. 2009. Bos taurus genome assembly. BMC Genomics 10:180.

Madsen, P., and J. Jensen. 2007. An user's guide to DMU. A package for analysing multivariate mixed models. Version 6 , release 4.7. http://dmu.agrsci.dk.

Melzer, N., D. Wittenburg, and D. Repsilber. 2013. Integrating milk metabolite profile information for the prediction of traditional 
milk traits based on SNP information for Holstein cows. PLoS ONE 8:e70256.

Poulsen, N. A., F. Gustavsson, M. Glantz, M. Paulsson, L. B. Larsen, and M. K. Larsen. 2012. The influence of feed and herd on fatty acid composition in 3 dairy breeds (Danish Holstein, Danish Jersey, and Swedish Red). J. Dairy Sci. 95:6362-6371.

Poulsen, N. A., I. Rybicka, H. D. Poulsen, L. B. Larsen, K. K. Andersen, and M. K. Larsen. 2015. Seasonal variation in content of riboflavin and major minerals in Danish organic and conventional dairy milk. Int. Dairy J. 42:6-11.

Powers, H. J. 2003. Riboflavin (vitamin B-2) and health. Am. J. Clin. Nutr. 77:1352-1360.

Reihl, P., and J. Stolz. 2005. The monocarboxylate transporter homo$\log$ Mch5p catalyzes riboflavin (vitamin $\mathrm{B}_{2}$ ) uptake in Saccharomyces cerevisiae. J. Biol. Chem. 280:39809-39817.

Rooke, J. A., J. F. Flockhart, and N. H. Sparks. 2010. The potential for increasing the concentrations of micro-nutrients relevant to human nutrition in meat, milk and eggs. J. Agric. Sci. 148:603-614.

Rutten, M. J. M., A. C. Bouwman, R. C. Sprong, J. A. M. van Arendonk, and M. H. P. W. Visker. 2013. Genetic variation in vitamin B-12 content of bovine milk and its association with SNP along the bovine genome. PLoS ONE 8:e62382.

Schennink, A., W. M. Stoop, M. H. P. W. Visker, J. M. L. Heck, H. Bovenhuis, J. J. van der Poel, H. J. F. van Valenberg, and J. A. M. van Arendonk. 2007. DGAT1 underlies large genetic variation in milk-fat composition of dairy cows. Anim. Genet. 38:467-473.

Schennink, A., W. M. Stoop, M. H. P. W. Visker, J. J. van der Poel, H. Bovenhuis, and J. A. M. van Arendonk. 2009. Short communication: Genome-wide scan for bovine milk fat composition. II Quantitative trait loci for long-chain fatty acids. J. Dairy Sci. 92:4676-4682.

Schwab, E. C., C. G. Schwab, R. D. Shaver, C. L. Girard, D. E. Putnam, and N. L. Whitehouse. 2006. Dietary forage and nonfiber carbohydrate contents influence B-vitamin intake, duodenal flow, and apparent ruminal synthesis in lactating dairy cows. J. Dairy Sci. 89:174-187.

Shingfield, K. J., V. Salo, E. Pahkala, V. Toivonen, S. Jaakkola, V. Piironen, and P. Huhtanen. 2005. Effect of forage conservation method, concentrate level and propylene glycol on the fatty acid composition and vitamin content of cows' milk. J. Dairy Res. 72:349-361.

Stoop, W. M., A. Schennink, M. H. P. W. Visker, E. Mullaart, J. A. M. van Arendonk, and H. Bovenhuis. 2009. Genome-wide scan for bovine milk-fat composition. I. Quantitative trait loci for short- and medium-chain fatty acids. J. Dairy Sci. 92:4664-4675.

Sunaric, S., M. Denic, and G. Kocic. 2012. Evaluation of riboflavin content in dairy products and non-dairy substitutes. Ital. J. Food Sci. 24:352-357.

Teo, Y. Y., M. Inouye, K. S. Small, R. Gwilliam, P. Deloukas, D. P. Kwiatkowski, and T. G. Clark. 2007. A genotype calling algorithm for the Illumina BeadArray platform. Bioinformatics 23:27412746 .

Theophilus, D. R., and O. E. Stamberg. 1945. The influence of breed, feed, and processing on the riboflavin content of milk. J. Dairy Sci. 28:259-268.

VanRaden, P. M. 2008. Efficient methods to compute genomic predictions. J. Dairy Sci. 91:4414-4423.

Van Tassell, C. P., T. P. L. Smith, L. K. Matukumalli, J. F. Taylor, R. D. Schnabel, C. T. Lawley, C. D. Haudenschild, S. S. Moore, W. C. Warren, and T. S. Sonstegard. 2008. SNP discovery and allele frequency estimation by deep sequencing of reduced representation libraries. Nat. Methods 5:247-252.

Yamamoto, S., K. Inoue, K. y. Ohta, R. Fukatsu, J. y. Maeda, Y. Yoshida, and H. Yuasa. 2009. Identification and functional characterization of rat riboflavin transporter 2. J. Biochem. 145:437-443.

Yang, J., B. Benyamin, B. P. McEvoy, S. Gordon, A. K. Henders, D. R. Nyholt, P. A. Madden, A. C. Heath, N. G. Martin, G. W. Montgomery, M. E. Goddard, and P. M. Visscher. 2010. Common SNPs explain a large proportion of the heritability for human height. Nat. Genet. 42:565-569.

Yonezawa, A., and K. i. Inui. 2013. Novel riboflavin transporter family RFVT/SLC52: Identification, nomenclature, functional characterization and genetic diseases of RFVT/SLC52. Mol. Aspects Med. 34:693-701.

Yonezawa, A., S. Masuda, T. Katsura, and K. Inui. 2008. Identification and functional characterization of a novel human and rat riboflavin transporter, RFT1. Am. J. Physiol. Cell Physiol. 295:C632-C641. 